\title{
Laboreal
}

Volume $8 \mathrm{~N}^{\circ} 1$ | 2012

Género, Atividades e Saúde

\section{Relações de gênero e gestão dos tempos : a articulação entre o trabalho profissional e doméstico em equipes de enfermagem no Brasil}

Relaciones entre los sexos y gestión del tiempo : la articulación entre el trabajo profesional y doméstico en los equipos de enfermería en Brasil Les rapports de genre et la gestion des temps : l'articulation entre le travail professionnel et domestique au sein d'équipes de soins infirmiers au Brésil Gender relations and time management : the articulation between professional and domestic work in nursing teams in Brazil

\section{Lúcia Rotenberg}

\section{OpenEdition}

\section{Journals}

\section{Edição electrónica}

URL: http://journals.openedition.org/laboreal/7218

DOI: $10.4000 /$ laboreal. 7218

ISSN: 1646-5237

\section{Editora}

Universidade do Porto

\section{Refêrencia eletrónica}

Lúcia Rotenberg, « Relações de gênero e gestão dos tempos : a articulação entre o trabalho profissional e doméstico em equipes de enfermagem no Brasil », Laboreal [Online], Volume $8 \mathrm{~N}^{0} 1$ | 2012, posto online no dia 01 julho 2012, consultado o 08 outubro 2019. URL : http:// journals.openedition.org/laboreal/7218; DOI : 10.4000/laboreal.7218

Este documento foi criado de forma automática no dia 8 outubro 2019

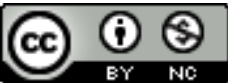

Laboreal está licenciado com uma Licença Creative Commons - Atribuição-NãoComercial 4.0 Internacional. 


\section{Relações de gênero e gestão dos tempos : a articulação entre o trabalho profissional e doméstico em equipes de enfermagem no Brasil}

Relaciones entre los sexos y gestión del tiempo : la articulación entre el trabajo profesional y doméstico en los equipos de enfermería en Brasil Les rapports de genre et la gestion des temps : l'articulation entre le travail professionnel et domestique au sein d'équipes de soins infirmiers au Brésil Gender relations and time management : the articulation between professional and domestic work in nursing teams in Brazil

\section{Lúcia Rotenberg}

\section{NOTA DO EDITOR}

Manuscrito recebido em : Fevereiro/2012

Aceite após peritagem : Julho/2012

A autora agradece aos pareceristas anônimos pelos comentários à primeira versão do texto. Agradece, ainda, ao CNPq (Conselho Nacional de Desenvolvimento Científico e Tecnológico), à FAPERJ (Fundação de Amparo à Pesquisa no Estado do Rio de Janeiro) e ao ITREOH International Training Program in Environmental and Occupational Health, pelo apoio financeiro a projetos de pesquisa. Durante a preparação deste artigo, a autora contou com bolsa de produtividade científica do CNPq (Proc. 308598/2009-1). 


\section{Introdução}

1 Este artigo tem por objetivo refletir sobre a articulação entre os tempos de trabalho nas esferas pública e doméstica com base em estudos empíricos com equipes de enfermagem de hospitais públicos brasileiros.

2 A organização do trabalho de enfermagem nestes hospitais torna este grupo interessante do ponto de vista da gestão dos tempos : fazem jornadas extensas - de 12 horas - intercaladas com folga de dois dias e meio (nos hospitais públicos). As folgas longas, aliadas à baixa remuneração dos profissionais da saúde no Brasil favorecem o engajamento em dois ou três empregos, aumentando substancialmente as jornadas de trabalho (Rotenberg, Portela, Banks, Griep, Fischer \& Landsbergis, 2008). O revezamento das equipes para cobrir a assistência ao longo das 24 horas demanda o trabalho noturno e nos fins de semana. Em alguns hospitais, se observa plantões de 24 horas a partir de arranjos formais ou informais entre os trabalhadores. Neste sentido, as equipes vivenciam os "desafios temporais" típicos dos trabalhadores em turnos, como o "desencontro" de horários em relação àqueles praticados socialmente e o desajuste fisiológico (Fischer, Moreno \& Rotenberg, 2003). As jornadas semanais extensas e as dificuldades decorrentes do trabalho noturno se somam às atividades voltadas para o âmbito doméstico neste grupo, majoritariamente feminino. Tais situações implicam estratégias de gerenciamento do tempo e de organização da vida cotidiana vivenciadas de forma complexa, em especial, pelas mulheres (Rotenberg, Griep, Pessanha, Gomes, Portela \& Fonseca, 2010 ; Cardoso, 2010).

\section{Tempo e tempos sob o prisma de interdependências}

3 Na obra Sobre o Tempo, Norbert Elias descreve o tempo como um símbolo social oriundo de um longo processo, através das gerações. A urbanização e expansão do comércio levaram à maior "necessidade de sincronizar o número crescente das atividades humanas, e de dispor de uma rede de referências temporais cuja extensão regular pudesse servir de quadro de referência" (Elias, 1998, p. 46).

4 Este autor observa que as civilizações da Antiguidade não tinham a mesma necessidade de medir o tempo que os Estados da era moderna ou as sociedades industrializadas atuais. Nestas, o tempo exerce uma coerção de fora para dentro que se manifesta sob a forma de relógios e calendários, que suscita uma autodisciplina nos indivíduos (Elias, 1998). Elias discorre sobre os processos históricos referentes à unificação dos calendários pelas autoridades eclesiásticas e políticas que detinham o monopólio da determinação do tempo. Com base nesta análise, argumenta que aquilo a a que chamamos 'tempo' constitui uma rede de relações, amiúde muito complexa, cuja determinação representa, em essência, uma síntese, uma atividade de integração e sincronização.

5 A questão de coordenar e sincronizar as atividades humanas remete ao próprio conceito eliasiano de sociedade : redes de interdependência mútua entre os indivíduos, que formariam as chamadas configurações (Elias, 1994a,b). Para Elias, as ações dos indivíduos são exercidas para outros indivíduos, de tal forma que cada pessoa vive em permanente dependência funcional de outras. Em resumo, as relações humanas formam interdependências que se modificam segundo a distribuição do poder (Elias, 
2008). Ao abordar o que denomina "ritmo" de nosso tempo, o autor analisa o papel do tempo nestas teias de interdependências. Através de exemplos de um empresário na profusão de encontros e reuniões, e de um operário em termos da duração de movimentos, observa que nestes dois casos

o ritmo é uma expressão do enorme número de ações interdependentes, da extensão e densidade das cadeias compostas de ações individuais e da intensidade dos conflitos que mantém em movimento toda essa rede interdependente. Em ambos os casos, a junção de tantas cadeias de ação exige uma alocação exata de tempo, levando as pessoas a subordinarem suas inclinações momentâneas às necessidades superiores de interdependência (Elias, 1993, pp. 207-208).

6 Na discussão sobre o tempo como construção social, Zarifian (2002) observa que é o caráter físico e quantitativo do tempo que permite regular os grandes conjuntos de interações sociais, orientar e sincronizar as pessoas entre si ou em relação a eventos. Trata-se de uma modalidade do tempo compartilhado da mesma forma por todos, que é apreendido de maneira quantitativa e neutra, sendo definido pelo autor como o tempo espacializado. Sua homogeneidade (as escalas de medida, como as horas têm o mesmo valor) destoa das características do tempo-devir, que é "simultaneamente objetivo e qualitativo" (Zarifian, 2002, p. 6). Este é um tempo ao qual ainda não sabemos ligar uma medida homogênea, que só podemos avaliar segundo nossos sentidos. Por exemplo, em um centro de chamadas telefônicas impõe-se aos operadores a redução do tempo de espera das chamadas e do tempo com cada cliente. Mas, ao interpretar as expectativas do cliente e a pertinência de suas respostas e, em função de sua consciência profissional, os trabalhadores podem ser menos rápidos se avaliarem que a qualidade da relação de serviço está em jogo (Zarifian, 2002). O autor chama a atenção para a complexidade da temporalidade ligada ao trabalho, o que demanda reconhecer ambas as modalidades do tempo como produtos sociais que se impõem.

7 Alvarez (2010) também analisa os diversos aspectos do tempo relacionado ao trabalho, como a jornada de jornada de trabalho, que decorre de uma norma contratada que regula a duração e os horários de atividade profissional (Alvarez, 2010; Quéinnec, 2007). Além da jornada, vista por Quéinnec (2007) como o tempo de trabalho, o autor chama a atenção para outros aspectos do tempo em relação ao trabalho: (i)o tempo dentro do trabalho, que se refere às exigências temporais da tarefa, ou seja, o ritmo de trabalho, (ii) o tempo no trabalho, relativo às diferentes reações ao longo da jornada, aos ritmos biológicos e (iii) tempo do trabalho, que confronta a temporalidade profissional e a temporalidade da vida fora do âmbito profissional.

0 uso do conceito de configuração de interdependências na análise das relações entre o trabalho e o tempo livre (ou de não-trabalho) implica que o que acontece no tempo de trabalho tem que ser interpretado em relação ao que acontece no tempo de lazer e, consequentemente quando um se modifica, o outro tem que se modificar também (Tabboni, 2001). Trata-se de um campo de tensão entre dois pólos que nunca se manifestam realmente em um estado puro, pois entre eles há um continuum de posições intermediárias. Segundo Elias, não há um tempo totalmente livre, mas um espectro de tempos livres porque, dentro da configuração feita pelos vários momentos do dia, as várias atividades são frequentemente superpostas. Assim, o chamado tempo livre engloba um número considerável de atividades de rotina e demanda um bom nível de auto-controle, incluindo atividades geradas pela organização doméstica. 
9 A discussão sobre a multiplicidade de tempos inseridos no tempo "livre" remete à complexidade e à coordenação dos tempos na esfera doméstica, como propõe Everingham (2002) ao analisar as relações entre tempos e gênero.

\section{O tempo na vida cotidiana como expressão das relações de gênero}

10 Na literatura sobre o tempo, a palavra em inglês "gender" tem sido utilizada como verbo ou adjetivo, como recurso para enfatizar as profundas relações entre o tempo e o gênero. No artigo Endengering Time, a autora chama a atenção para o quanto homens e mulheres têm experiências diferentes sobre as relações entre os tempos voltados para as esferas pública e privada (Everingham, 2002). Para Perista (2010), "o tempo é 'genderizado"' (p. 49), no sentido de atuar como uma dimensão-chave nas análises sobre as (des)igualdades de gênero. O tempo é resultado de uma "construção social, constituída por e constitutiva de relações sociais", sintetiza Perista (2002, p. 447).

11 No cerne destas abordagens está a divisão sexual do trabalho, forma de divisão do trabalho social adaptada historicamente nas diversas sociedades, cujas características são a atribuição prioritária da esfera produtiva aos homens, e a esfera reprodutiva às mulheres (Hirata \& Kergoat, 2008). Para estas autoras, tal conceituação se fundamenta em dois princípios básicos: o da separação no sentido da diferenciação entre os trabalhos tidos como masculinos e femininos, e o princípio hierárquico, associado ao menor valor do trabalho feminino, em função de sua associação a atividades que envolvem qualidades natas das mulheres e, portanto, não ligadas à qualificação (Kergoat, 2009).

12 Neste contexto, Everingham (2002) considera a articulação entre o tempo vendido pelos homens ao mercado de trabalho e trabalho doméstico realizado pelas mulheres, ressaltando a complexidade deste último. Para esta autora, a experiência doméstica do tempo abarca múltiplas temporalidades no sentido de lidar com atividades regidas pela duração da tarefa (mais do que pelo horário do relógio), mas cujo fluxo temporal é influenciado pelos horários de trabalho ou outras atividades dos demais membros da família (Everingham, 2002 ; Cyrino, 2010). Desta forma, homens e mulheres vivenciam a divisão entre os espaços público e privado diferentemente, devido às suas relações diferenciadas com estas duas esferas.

13 É este o argumento de Bandeira (2010) em relação ao valor das estatísticas sobre o uso do tempo: a diversidade de alocação temporal em homens e mulheres permite conhecer a dinâmica das relações de poder existentes entre os sexos ou, em outras palavras, a dinâmica da divisão sexual do trabalho.

\section{Breve descrição dos métodos}

14 As pesquisas descritas neste artigo foram realizadas entre 2000 e 2010 em hospitais públicos no Rio de Janeiro, Brasil. Inserem-se no campo da Saúde do Trabalhador, tendo como referência central o processo de trabalho e suas repercussões à saúde (Brito, 2004 ; Minayo-Gomes \& Lacaz, 2005). É um campo que demanda a articulação entre áreas do conhecimento, no sentido de ampliar as formas de abordagem das relações entre o trabalho e a saúde. Tal ampliação inclui, por exemplo, valorizar a subjetividade 
dos trabalhadores, assim como, incorporar a Epidemiologia Social como instrumento de análise dos objetos de estudo (Araújo, 2011). Trata-se de buscar um enfoque inter e transdisciplinar capaz de apreender as implicações à saúde derivadas do trabalho, em especial, no contexto atual do setor saúde no Brasil, expresso na intensificação dos ritmos de trabalho, com aumento da precarização e fragilização do emprego e do salário (Souza, 2010).

A elaboração dos estudos teve como fio condutor o uso de aportes teóricometodológicos voltados para a articulação entre os tempos de trabalho nas esferas profissional e doméstica. Dado o caráter regulador do tempo na vida social (Elias, 1998), partiu-se da concepção de que a análise do tempo tal como vivido por homens e mulheres é reveladora dos valores e das relações de poder daquela sociedade naquele contexto específico (Elias, 1987). Foram utilizadas técnicas de cunho qualitativo e quantitativo com vistas a iluminar aspectos objetivos e subjetivos dos tempos de trabalho.

Os trabalhos de campo tiveram como foco as equipes de enfermagem (enfermeiras, técnicas e auxiliares de enfermagem) que atuavam nos hospitais independentemente do tipo de vínculo profissional. Todos os contatos com os trabalhadores foram realizados nos próprios hospitais, durante a jornada de trabalho. Os resultados foram publicados na forma de artigos ou divulgados como dissertações de mestrado ou como monografia de conclusão da graduação em Psicologia.

Uma das técnicas quantitativas se baseou nos chamados diários de usos do tempo (Szalai, 1972 ; Aguiar, 1997), instrumentos nos quais os trabalhadores registravam suas atividades ao longo das 24 horas. No presente estudo, foram eleitas as seguintes atividades : trabalho (em todos os locais), sono, descanso, lazer, trabalho doméstico, deslocamentos, cuidado de si (higiene, refeições, atividade física), cuidado de outro (crianças, outras pessoas), trabalho não remunerado e estudos. Este instrumento era preenchido por, pelo menos, quatro dias consecutivos, mas vários trabalhadores o preencheram por até uma semana. Este material abrangeu um total de 120 profissionais de enfermagem de um hospital público.

Os estudos epidemiológicos constituíram outra modalidade de estudo quantitativo. Baseavam-se em questionários aplicados na forma de censo, ou seja, de forma a abranger o conjunto de trabalhadores da enfermagem que prestavam assistência aos pacientes. A primeira ocasião de estudo (em 2000) abrangeu 280 trabalhadores de dois hospitais, enquanto a segunda (em 2005/2006) incluiu um total de 1509 profissionais da enfermagem de três hospitais. Foi utilizado um questionário abrangente que apresentava perguntas sobre o trabalho e a saúde, incluindo aspectos do sono e da necessidade de recuperação em relação ao trabalho (v. adiante). Considerando a preocupação central de investigar a articulação entre as esferas profissional e doméstica, foram priorizados na construção do texto os resultados sobre a necessidade de recuperação, que pudessem refletir a possível influência do trabalho doméstico sobre o descanso e o sono.

19 A necessidade de recuperação após o trabalho busca avaliar o grau com que o processo de trabalho induz sintomas de fadiga, irritabilidade e sinais de sobrecarga (Van Veldhoven, 2008). Esta avaliação é feita a partir de uma escala composta por 11 itens como, por exemplo, "Eu tenho dificuldade de relaxar após um dia de trabalho" em relação aos quais os trabalhadores selecionam uma resposta afirmativa ou negativa. Os resultados desta escala permitem classificar os trabalhadores em relação ao quanto se 
sentem recuperados - boa recuperação, que corresponde à recuperação considerada suficiente e má recuperação, ou recuperação insuficiente. Embora tenha sido elaborada para avaliar a recuperação em função de variáveis ocupacionais (turno de trabalho, por exemplo), partimos da perspectiva de que o trabalho doméstico influenciaria de forma importante a recuperação das trabalhadoras.

Outras questões do trabalho profissional incluíram aspectos específicos relacionados aos plantões noturnos, tendo em vista os desafios temporais decorrentes do trabalho noturno em termos do organismo e da vida social (Fischer, Moreno \& Rotenberg, 2003). Foram analisados o número de noites de trabalho, a permissão ou não para o repouso durante os plantões e, em caso afirmativo, o tempo de sono durante os plantões. 0 questionário também incluía dados sobre os fatores psicossociais no trabalho associados aos modelos teóricos de demanda-controle (Karasek, 1979) e desequilíbrio esforço-recompensa (Siegrist, 1996).

21 A informação sobre a jornada semanal de trabalho era obtida a partir da consulta aos trabalhadores sobre o tempo dedicado ao trabalho profissional (em todos os locais) ao longo de uma semana consecutiva, sendo a informação fornecida dia a dia (ontem, anteontem e assim por diante). Os trabalhadores também foram solicitados a responder sobre o quanto dispunham de tempo para tinham tempo para as tarefas da casa, para o repouso durante a semana, para o lazer nos dias de folga e para cuidar de si, considerando sua jornada de trabalho profissional (Portela, Rotenberg \& Waissmann, 2005).

22 A dedicação às tarefas domésticas foi avaliada através de dois procedimentos. O primeiro é análogo ao cômputo da jornada profissional, ou seja, através da informação dia a dia sobre o tempo dedicado às tarefas ligadas ao âmbito doméstico. A segunda avaliação corresponde ao cálculo da sobrecarga doméstica, que considera o número de moradores na residência (excluindo a própria profissional) e o grau de responsabilidade da pessoa em relação aos quatro tipos básicos de tarefas domésticas - limpar a casa, cozinhar, lavar e passar roupa (Aquino, 1996). O uso destes dois instrumentos para o cômputo do trabalho doméstico decorre de observações anteriores em que observamos diferenças entre as duas formas de avaliação (Portela, Rotenberg \& Waissmann, 2005).

Duas técnicas foram utilizadas nos estudos qualitativos. Um delas baseia-se em entrevistas individuais com trabalhadoras dos setores de internação, ou seja, aqueles que demandam funcionamento de forma ininterrupta 24 horas por dia. Como o foco central destes estudos era a organização da vida cotidiana em pessoas cujo horário de trabalho diferia daquele praticado pelas pessoas de seu meio sociofamiliar, priorizamos investigar mulheres que atuavam nos plantões noturnos. Foram realizadas cerca de 30 entrevistas que foram gravadas e posteriormente transcritas para análise (Soares, 2005 ; Ribeiro-Silva, 2006).

Outra técnica de cunho qualitativo se refere à realização de Encontros de Discussão sobre as relações entre o trabalho e a saúde. Estes Encontros buscavam promover diálogos a partir dos resultados dos estudos epidemiológicos acima descritos (Pessanha, 2009). Os Encontros de Discussão tinham como dispositivos de análise os resultados dos questionários em forma de gráficos e figuras, além de figuras da Internet e outras. A proposta dos Encontros é fruto de reflexões alinhadas com a Ergologia (Schwartz, 2000), que propõe a articulação entre três pólos: (i) o pólo dos conceitos, que constitui os materiais oriundos das disciplinas científicas, (ii) o pólo relativo às experiências e saberes dos trabalhadores em suas atividades e (iii) o pólo do compromisso ético. "Este 
terceiro pólo é a liga do dispositivo, pois trata da ética necessária à construção das relações de parceria em terminada filosofia da humanidade, numa maneira de ver o outro como seu semelhante" (Brito, 2004, pp. 101-102).

Também contribuiu para a elaboração destas atividades o aporte teórico-metodológico da Análise Institucional (Lourau, 1993), cujas ferramentas possibilitam questionar criticamente o processo de trabalho enquanto processo dinâmico, que é produzido e que produz ao mesmo tempo. Entende-se que os trabalhadores detêm um saber sobre o seu trabalho que se acrescenta ao conhecimento científico, e vice-versa, numa relação de produção de conhecimentos acerca do processo de trabalho, neste caso, sobre os tempos de trabalho.

A disponibilização dos resultados dos questionários para uma análise dialógica entre trabalhadores e pesquisadores permite ao grupo ver estes resultados como dados "em construção" - e não verdades absolutas decorrentes do poder soberano da academia, o que contribui para a formação de pesquisadores e de trabalhadores (Pessanha, 2009; Ferreira, Osório da Silva \& Rotenberg, 2012). Toda a equipe de enfermagem foi convidada a participar destes Encontros, reunindo-se um número variável de trabalhadores e pesquisadores em 10 ocasiões.

\section{Análises a partir do campo empírico}

No material oriundo das entrevistas, as tarefas realizadas no âmbito doméstico foram frequentemente ligadas ao trabalho profissional sendo por vezes nomeadas como trabalho, como mostram exemplos extraídos dos estudos de Ribeiro-Silva (2006) e Soares (2005), respectivamente :

“... O tempo todo a gente está trabalhando, quer seja em casa ou no trabalho. A qualquer hora você está trabalhando, a não ser na hora que você está na cama dormindo ou descansando. De resto, está trabalhando..." Rose, enfermeira

"Esse cansaço é porque eu trabalho lá, trabalho aqui, trabalho na minha mãe... então, eu estou com uma carga de trabalho nos últimos três anos, muito grande. Eu trabalho todos os dias, eu levanto cedo... cedo, todos os dias....Todos os dias eu trabalho, acordo cedo... e todos os dias eu estou na rua. Eu estou na rua de manhã, eu estou na rua de noite... eu estou podre de cansada, eu me sinto cansada. Um cansaço que não adianta eu dormir que eu não descanso, porque o cansaço vem da mente." Alice, técnica de enfermagem

Estas falas remetem ao comentário de Adam (1995) sobre as experiências do tempo em esposas e mães, que não se encaixam em perspectivas que separam o trabalho do lazer, o tempo público do privado, o tempo subjetivo do tempo objetivo, a tarefa em relação ao tempo do relógio. Há, na visão desta autora, uma incompatibilidade deste tempo "doméstico" com o tempo de trabalho avaliado em unidades finitas, um tempo uniforme e abstrato que pode ser medido, quantitativamente avaliado, controlado e trocado por recursos financeiros. Como observado por Davies (1990), as mulheres percebem seu tempo como se estivessem de sobreaviso 24 horas por dia, ou seja, seguem uma lógica temporal não econômica, no sentido de não serem sujeitas a horários e prazos, enfim, se vêem como continuamente disponíveis. Esta diferenciação também foi observada entre as trabalhadoras da enfermagem, cujos discursos 
apresentavam pares de oposição, ressaltando o trabalho profissional como aquele em que há uma carga horária e do qual a pessoa pode sair, enquanto o trabalho doméstico não tem horário ou, como refere a trabalhadora "quanto mais você faz, mais coisa aparece" (Ribeiro-Silva, 2007).

A reflexão de uma enfermeira durante uma entrevista sobre um possível dia que durasse 30 horas ilustra as várias facetas do tempo, através de um discurso em que avalia que não faria diferença, já que ainda assim trabalharia todo o tempo (RibeiroSilva, 2007). A insuficiência ou inadequação dos números para apreender todos os aspectos da vivência do tempo remete aos aspectos subjetivos do tempo, vistos por Adam (1990) como essenciais na análise da temporalidade. Trata-se da subjetividade do tempo, ou seja, o tempo que varia de acordo com a experiência, enquanto o tempo objetivo é aquele do relógio e do calendário no qual cada hora tem duração uniforme (Hassan \& Purser, 2007). Destaca-se aqui o convívio simultâneo entre o chamado tempo espacializado expresso pelo relógio e o tempo qualitativo e psicológico, que remete ao tempo-devir no sentido atribuído por Zarifian (2002).

A complexidade na lida com o tempo é abordada por Everingham (2002), que chama a atenção para um aspecto peculiar do seu próprio tempo, que identifica como comum a muitas mulheres: a necessidade de disponibilizar um tempo antes que este possa ser utilizado. Observamos relatos nesta direção como o de uma técnica de enfermagem do plantão noturno que descreve todas as suas ações entre o trabalho em um hospital e noutro. O tempo entre os dois hospitais é utilizado para lavar, passar e cozinhar, além de resolver assuntos domésticos fora do domicílio. Trata-se, enfim, de organizar e planejar tudo com antecedência, considerando não só o próximo plantão, mas também o horário de escola dos filhos. Sua descrição é um exemplo da organização e coordenação necessárias entre várias atividades. Como observa Everingham (2002), os limites temporais entre as esferas pública e privada

\footnotetext{
“são profundamente 'genderizados' (ou sexualizados), com a vida pública regida de acordo com o relógio e as mulheres organizando o tempo na esfera privada para que os membros da família participem da esfera pública, coordenando os tempos da vida cotidiana de forma a se ajustar aos múltiplos 'tempos' dos familiares" (Everingham, 2002, p. 339, tradução livre).
}

31 Na continuidade da fala desta técnica de enfermagem, o momento de descanso é associado a situações em que não há outras tarefas a serem realizadas. Esta característica da organização da vida cotidiana vai ao encontro de dados quantitativos obtidos através de questionários, que revelam o quanto a queixa de falta de tempo para si está relacionada à alta sobrecarga doméstica (Portela, Rotenberg \& Waissmann, 2005). Nesta mesma direção, os diários de uso do tempo mostram o maior tempo despendido em atividades domésticas e de cuidado de outros entre as trabalhadoras com filhos (em especial de até 10 anos) em detrimento do tempo para si próprias, que corresponde àquele ligado ao lazer e cuidados de si (Ribeiro-Silva \& Rotenberg, 2008).

Nos Encontros de Discussão dos resultados epidemiológicos, um diálogo nos chamou atenção em relação aos plantões realizados de noite e de madrugada. Na descrição da vida cotidiana, a divisão do trabalho doméstico foi o foco da fala de uma trabalhadora cujo marido fazia plantões naquele hospital, nas mesmas noites que ela (Pessanha, 2009). Ao comentar sobre a volta para casa após o trabalho, ela refere - através de um relato que parecia misturar naturalização e indignação - a prática de cuidar dos filhos 
enquanto o marido costumava dormir. Se a naturalização demonstrada na fala da trabalhadora aponta para a divisão sexual do trabalho como algo inexorável e imutável (Kergoat, 2003), por outro lado sua indignação questiona esta divisão em função da qual o ato de dormir do marido se articula de forma relacional à execução das tarefas domésticas por ela. $\mathrm{O}$ aporte conceitual de Elias é útil neste contexto, pois podemos pensar o casal como seres interdependentes, buscando analisar o equilíbrio de poder entre eles. Significa pensar em um padrão mutável a partir de tensões que estão presentes em todas as relações sociais (Elias, 2008). Em sendo um padrão mutável, as possibilidades de mudanças ou de perpetuações dependem do jogo de forças vigente em cada contexto social, pois "todos organizam o seu tempo, seu dia, sua vida, seu papel na história de maneira mais ou menos livre e individual, mas ao mesmo tempo em obediência a constrangimentos em função de sua posição social, seus recursos físicos, o período histórico em que vive" (Tabboni, 2001, p. 11, tradução livre). Trata-se aqui de uma aproximação entre a conceituação da divisão sexual do trabalho como relação social com seus antagonismos, oposições, dominação e opressão (Ávila, 2010) e os conceitos elaborados por Elias em termos de uma configuração de seres interdependentes que só podem ser compreendidas naquele contexto de tensões específicas.

33 Cabe considerar, neste contexto, a afirmativa de Hirata e Kergoat (2008) sobre a divisão sexual do trabalho como "um fator prioritário para a sobrevivência da relação social entre os sexos" (p. 266). Ao observar a validade dos princípios de separação e hierarquização para todas as sociedades conhecidas, ressaltam o quanto não se trata, no entanto, de um dado imutável. Assim, a designação prioritária dos homens à esfera produtiva e das mulheres à esfera reprodutiva é modulada histórica e societalmente, demonstrando plasticidade nos diferentes contextos de tempo e espaço. A este respeito, cabe observar as características singulares da relação social de sexo, tal como propõe Kergoat (2003) : "ela é estruturante para o conjunto do campo social e transversal à totalidade deste campo - o que não é o caso do conjunto das relações sociais. Podemos, então, considerá-la um paradigma das relações de dominação" (p. 59). No presente estudo, nos chama a atenção a aparente "impermeabilidade" da divisão do trabalho doméstico, mesmo na situação peculiar em que ambos - trabalhadora e trabalhador passam a noite no hospital. Desta forma, a possível sobrecarga decorrente do trabalho noturno não parece mediar as práticas ligadas à organização da vida cotidiana, o que se assemelha ao observado em outro campo empírico, com operárias e operários que trabalhavam à noite em uma fábrica de plásticos (Rotenberg, Portela, Marcondes \& Moreno, 2001). Ocorre, inclusive, o contrário, ou seja, a própria escolha dos plantões noturnos como fruto da vinculação das mulheres à esfera doméstica e às atividades de cuidado (Soares, 2005). Neste caso, trata-se, de "deslocar" a realização do trabalho no(s) hospital(ais) para os horários em que os familiares requerem menos cuidado, por ser o horário socialmente vinculado ao sono. Assim, a escolha pelos plantões noturnos pode ser vista como uma estratégia de gestão dos tempos no sentido de favorecer a conciliação das demandas nas esferas doméstica e profissional e considerando o vínculo com a esfera doméstica no tange ao cuidado de outras pessoas.

A este respeito, Carrasco e Mayordomo (2005) comentam sobre as decisões das mulheres quanto à organização dos seus horários (no mercado de trabalho e no meio doméstico) que geralmente levam em conta o bem estar de outros membros da família. Desta forma, há que se analisar o trabalho profissional e doméstico sob uma forma relacional, como propõe Aguiar (1997). O material apresentado sobre as equipes de 
enfermagem sugere que as atividades domésticas, em especial o cuidado de outras pessoas, assume um caráter de centralidade no sentido de este nortear as decisões, o que não foi observado no estudo desenvolvido por Cyrino (2010) em relação a mulheres que atuavam em casa e no mercado de trabalho em ocupações diversas.

Análises quantitativas sobre a necessidade de recuperação em relação à fadiga decorrente do trabalho profissional auxiliam a desvendar alguns aspectos da interação entre o trabalho nas esferas pública e privada. Em um grupo de 1307 mulheres, a recuperação considerada insuficiente foi mais frequente entre aquelas que apresentavam jornada doméstica extensa em si, ou conjugada a longas jornadas profissionais (Rotenberg et al., 2010). Estes resultados ressaltam o caráter essencial de considerar o âmbito doméstico nas investigações sobre as relações trabalho-saúde em grupos femininos.

Cabe observar os aspectos da recuperação em relação ao trabalho entre os trabalhadores que atuam nos plantões noturnos. Destaca-se aqui a gestão coletiva nas enfermarias, em que os trabalhadores se revezam, a partir de negociações entre eles, para usufruir de períodos de até três horas de descanso (Soares, 2005). Trata-se do que a Ergonomia conceitua como estratégia de regulação (Guérin, Laville, Daniellou, Duraffourg \& Kerguelen, 2001), em que diante das variabilidades presentes no trabalho os trabalhadores buscam estratégias para atender às exigências do trabalho. É um meio de lidar com a dificuldade de exercer a atividade exigida, expressa na interação entre a queda na vigilância decorrente da ritmicidade circadiana e a privação do sono (Verdier, Barthe \& Quéinnec, 2003). Desta forma, o revezamento dos trabalhadores para o descanso pode ser visto como uma regulação organizacional que implica nova distribuição (ou reprogramação) das tarefas dos que se mantém nos postos de trabalho (Quéinnec, 2007).

37 Neste contexto, estudamos as trabalhadoras dos plantões noturnos considerando o sono no trabalho e o trabalho doméstico. As análises revelaram que a recuperação vista como suficiente foi mais frequente entre as trabalhadoras que relatam dormir por duas a três horas durante os plantões (comparadas às que não dormiam ou o faziam por menos de duas horas), porém apenas entre aquelas com jornadas domésticas curtas (de até 10 horas semanais). Desta forma, a alta carga de trabalho doméstico parece neutralizar os aspectos benéficos do repouso durante o plantão noturno na recuperação das trabalhadoras, revelando as complexas relações entre as esferas profissional e doméstica (Silva-Costa, Rotenberg, Griep \& Fischer, 2011). Neste sentido, analisar a recuperação das trabalhadoras articulada ao sono durante a jornada noturna e às atividades ligadas à casa remete aos diversos componentes do tempo profissional, em particular no que tange aos horários, como descreve Quéinnec (2007). É um tempo de 12 horas (de 19:00 às $7: 00 \mathrm{~h}$ ), cujo momento de ocorrência desafia as características temporais da fisiologia humana, evidenciando a interrelação entre a vida de trabalho $\mathrm{e}$ a vida fora do trabalho.

Para Hirata e Zarifian (2003), os tempos voltados para o trabalho remunerado e a produção do viver se interpenetram sem, no entanto, se confundirem. Assim, observam que a entrada maciça das mulheres no mercado de trabalho é uma forma de avançar no espaço social em que os homens inscreveram sua dominação. E ao lidar com os limites temporais que se redobram no mundo profissional e doméstico, as mulheres estão em condições de questionar as esferas da vida que regem a sociedade moderna. 
39 A este respeito, Hirata (2006) comenta sobre o papel dos estudos empíricos no reconhecimento de uma característica constitutiva do trabalho doméstico, como relação de 'disponibilidade permanente' à família, o que na visão da autora aponta para a dimensão da afetividade, do amor, que está no cerne do exercício do care no interior da família. Para ela, a dificuldade em lutar contra a divisão sexual do trabalho doméstico está justamente na dimensão de afetividade, que cria uma relação de 'servidão voluntária' das mulheres.

\section{Considerações finais}

40 A elaboração dos estudos partiu da concepção de que ao gerar constrangimentos do tempo diferentes para homens e mulheres, a divisão sexual do trabalho tem implicações diferenciadas segundo o gênero dos trabalhadores. Em conjunto, o material apresentado remete ao comentário de Brito (2005) sobre o conceito de divisão sexual do trabalho, que permite apreender o trabalho em "seus aspectos sociais, econômicos, organizacionais e subjetivos, exigindo a conjugação de diferentes análises teóricas para sua análise" (Brito, 2005 ; p. 886). A autora ressalta a posição de Haicault (1984) sobre o trabalho mental decorrente da realização de tarefas ligadas à produção e reprodução, o que se coaduna com o esforço vivido pelas mulheres na gestão dos tempos dedicados às duas esferas. Trata-se das pressões do tempo já que a alternância trabalho/tempo livre por vezes não é experimentada pelas trabalhadoras (Brito, 2005).

41 A análise empreendida por Brito (2005) sobre a noção canguilheniana de saúde (Canguilhem, 2009) aplicada ao trabalho se revela útil, uma vez que a centralidade da esfera doméstica para as mulheres pode levar à menor possibilidade de criar novas normas para lidar com as demandas da interface profissional-doméstico. Neste sentido, há que se considerar as implicações à saúde, pois nas palavras da autora a má saúde corresponde à "limitação do poder de tolerância e de compensação das agressões ambientais" (Brito, 2005 ; p. 884). Embora o texto não se atenha a dados de morbidade, o material avaliado aponta possíveis relações com a saúde física e mental. Aspectos da articulação entre o trabalho profissional, a esfera doméstica e a saúde, incluindo dados do estresse psicossocial no trabalho em equipes de enfermagem são apresentados por Araújo, Aquino, Menezes, Santos e Aguiar (2003), Araújo e Rotenberg (2011) e Portela (2012).

42 Os resultados confirmam o quanto a atuação destas mulheres no mercado de trabalho em nada as desobriga da responsabilidade sobre o trabalho doméstico (Cyrino, 2009; Ávila, 2010). Neste sentido, chama a atenção a aparente "impermeabilidade" da divisão do trabalho doméstico, inclusive no que concerne a trabalhadoras que fazem plantões noturnos. Como comenta Oliveira (2001) na obra Reengenharia do tempo, "há aqui um problema da sociedade, não resolvido, e não um problema das mulheres" (Oliveira, 2001, p. 27). Para esta autora, a verdadeira dificuldade está na articulação entre a vida privada e a vida pública, e não dentro da vida privada por causa da vida pública.

43 Mais do que revelar um acúmulo de trabalhos entre as mulheres, a análise das imbricações entre gênero e tempos de trabalho(s) alimenta discussões sobre políticas sociais voltadas para a reprodução social (Dedecca, 2004). Se as assimetrias ligadas ao gênero podem parecer óbvias, transformadas em objeto de estudo elas contribuem para tornar visível o caráter social desta construção e, portanto, a possibilidade de desconstrução, alimentando a discussão sobre a igualdade de gênero. Trata-se de focar 
um dos objetivos do Milênio (United Nations Development Programme, 2002) no sentido da elaboração de estratégias e políticas voltadas para a igualdade de gênero e emponderamento das mulheres, incluindo aquelas voltadas para a conciliação do trabalho profissional e vida familiar (Perrons, Fagan, McDowell, Ray \& Ward, 2005).

Se por um lado, a entrada das mulheres no universo público pode ser interpretada como um movimento na direção de uma mudança nas relações de poder entre homens e mulheres, por outro sua atuação como principal (ou único) responsável pelas tarefas domésticas traduz a manutenção das desigualdades de gênero na distribuição dos tempos (Dedecca, 2008). E problemas de poder expressam "equilíbrios de poder instáveis e que, portanto, podem evoluir" (Elias, 2001, p. 157).

Entre os sinais de mudanças no Brasil está a incorporação do trabalho doméstico nas pesquisas realizadas pelo órgão oficial de estatísticas (Instituto Brasileiro de Geografia e Estatística), o que reflete o reconhecimento do trabalho no âmbito familiar como parte essencial da vida em sociedade. $O$ uso destas informações para a implementação de políticas públicas remete a um horizonte potencialmente mais igualitário (Bandeira, 2010). São muitas as facetas do tempo e, portanto, múltiplas as contribuições dos estudos empíricos (Nowotny, 1992) e podemos completar, dos movimentos sociais. Cabe às sociedades construir formas de uso do tempo compatíveis com a ética contemporânea, voltada para valores de justiça e igualdade.

\section{BIBLIOGRAFIA}

Adam, B. (1990). Time and Social Theory. Cambridge : Polity Press.

Adam, B. (1995). Timewatch. The Social Analysis of Time. Cambridge : Polity Press.

Aguiar, N. (1997). Gênero e Ciências Humanas. Desafio às Ciencias Desde a Perspectiva das Mulheres. Rio de Janeiro : Rosa dos Tempos.

Alvarez, D. (2010). Tempo. Laboreal, 6, (2), 71-75. http://laboreal.up.pt/revista/artigo.php? $\mathrm{id}=37 \mathrm{t} 45 \mathrm{nSU} 5471123: 4141: 584321$

Aquino, E.M.L. (1996). Gênero, trabalho e hipertensão arterial : um estudo de trabalhadoras de enfermagem em Salvador, Bahia. Tese de Doutoramento, Instituto de Saúde Coletiva da Universidade Federal da Bahia, Bahia, Brasil.

Araújo, T.M. (2011). Revisão de Abordagens Teórico-Metodológicas sobre Saúde mental e Trabalho. In : Carlos Minayo Gomez, Jorge Mesquita Huet Machado e Paulo Gilvanes Lopes Pena (Orgs.), Saúde do Trabalhador na Sociedade Brasileira Contemporânea (pp. 325- 343). Rio de Janeiro : Editora Fiocruz.

Araújo, T.M., \& Rotenberg, L. (2011). In : Ada Ávila Assunção e Jussara Brito (Orgs.), Trabalhar na saúde : experiências cotidianas e desafios para a gestão do trabalho e do emprego (pp. 131-150). Rio de Janeiro : Editora Fiocruz. 
Araújo, T.M., Aquino, E., Menezes, G., Santos, C.O. \& Aguiar, L. (2003). Aspectos psicossociais do trabalho e distúrbios psíquicos entre trabalhadoras de enfermagem. São Paulo : Revista de Saúde Pública. 37 (4), 424-433.

Ávila, M.B. (2010). O tempo do trabalho produtivo e reprodutivo na vida cotidiana. Revista ABET, 9, (2), 53-70

Bandeira, L. (2010). Importância e motivações do Estado Brasileiro para pesquisas de uso do tempo no campo de gênero. Revista Econômica, 12, (1), 47-63.

Brito, J. (2004). Saúde do trabalhador : reflexões a partir da abordagem ergológica. In : Marcelo Figueiredo, Milton. Athayde, Jussara Brito e Denise Alvarez (Orgs.), Labirintos do trabalho: interrogações e olhares sobre o trabalho vivo (pp. 91-114). Rio de Janeiro : DP\&A.

Brito, J. (2005). Trabalho e Saúde Coletiva : o ponto de vista da atividade e das relações de gênero. Ciência \& Saúde Coletiva, 10, (4), 879-890.

Canguilhem, G. (2009). 0 normal e o patológico. Rio de Janeiro : Forense Universitária.

Cardoso, A.C.M. (2010). Os trabalhadores e suas vivências cotidianas. Dos tempos de trabalho e de não-trabalho. Revista Brasileira de Ciências Sociais, 25, (72), 101-117.

Carrasco, C., \& Mayordomo,M. (2005). Beyond Employment. Working time, living time. Time \& Society, 14(2/3), 231-259.

Cyrino, R. (2009). Trabalho, temporalidade e representações sociais de gênero : uma análise da articulação entre trabalho doméstico e assalariado. Sociologias (UFRGS), 11, (21), 66-92.

Cyrino, R. (2010). A construção social da temporalidade e a articulação entre trabalho doméstico e assalariado : o caso das mulheres executivas. Tese de Doutoramento em Sociologia, Universidade Federal de Minas Gerais, Belo Horizonte, Brasil.

Davies, K. (1990). Women and time. The weaving of the stands of everyday life. Aldershot : Avebury. Dedecca, C. S. (2008). Regimes de Trabalho, uso do tempo e desigualdade entre homens e mulheres. In : Albertina de Oliveira Costa, Bila Sorj, Cristina Bruschini, Helena Hirata (Orgs.), Mercado de Trabalho e gênero : comparaçôes internacionais (p. 279-297). Rio de Janeiro : Ed. FGV.

Dedecca, C. S., Ribeiro, C.S.M.F., \& Ishii, F.J. (2009). Gênero e jornada de trabalho : análise das relações entre mercado de trabalho e família. Trabalho, Educação e Saúde, 7,(1), 65-90.

Dedecca, C.S. (2004). Tempo, Trabalho e Gênero. In : Ana Alice Costa, Eleonora Menicucci, Maria Ednalva Bezerra de Lima e Vera Soares (Orgs.), Reconfiguração das relações de gênero no trabalho (pp. 21-52). São Paulo : CUT Brasil.

Elias, N. (1987). The Changing Balance of Power between the Sexes - A Process-Sociological Study : The Example of the Ancient Roman State. Theory, Culture \& Society, 4, 287-316.

Elias, N. (1993). o Processo Civilizador, vol II : Formação do Estado e Civilização. Rio de Janeiro : Jorge Zahar Editor.

Elias, N. (1994a). A Sociedade dos Indivíduos. Rio de Janeiro : Jorge Zahar Ed.

Elias, N. (1994b). o Processo Civilizador, vol I : Uma história dos costumes. Rio de Janeiro : Jorge Zahar Editor.

Elias, N. (1998). Sobre o Tempo. Rio de Janeiro : Editora Jorge Zahar.

Elias, N. (2001). Norbert Elias por ele mesmo. Rio de Janeiro : Jorge Zahar Editor.

Elias, N. (2008). Introdução à Sociologia. Lisboa : Edições 70. 
Everingham, C. (2002). Engendering Time. Gender equity and discourses of workplace flexibility. Time \& Society, 11,(2/3), 335-351.

Ferreira, J. P., Osorio da Silva, C., \& Rotenberg, L. (2012). Proposal for training of workers and researchers as from the participatory return of research results in workers' health. Work, 41, 4584-4589.

Fischer, F.M., Moreno, C.R.C. \& Rotenberg, L. (Orgs.) (2003). O trabalho em turnos e noturno na sociedade 24 horas. São Paulo : Editora Atheneu.

Guérin, F., Laville, A., Daniellou, F. Duraffourg, J., \& Kerguelen, A. (2001). Compreender o trabalho para transformá-lo. São Paulo : Edgar Blücher.

Haicault, M. (1984). La gestion ordinaire de la vie en deux. Sociologie du Travail, 3, 268-277.

Hassan, R. \& Purser, R.E. (2007). 24/7 Time and Temporality in the Network Society. Standford : Standford University Press.

Hirata, H. \& Zarifian, P. (2003). O conceito de trabalho. In : Marli Emílio, Marilane Teixeira, Miriam Nobre e Tatau Godinho (Orgs.), Trabalho e cidadania ativa para as mulheres : desafios para as Políticas Públicas (pp. 64-69). São Paulo : Coordenadoria Especial da Mulher.

Hirata, H. (2006). Entrevista : Helena Hirata. Trabalho, Educação e Saúde, 4(1), 199-203.

Hirata, H., \& Kergoat, D. (2008). Divisão sexual do trabalho profissional e doméstico : Brasil, França, Japão. In : Albertina de Oliveira Costa, Bila Sorj, Cristina Bruschini, Helena Hirata (Orgs.), Mercado de Trabalho e gênero : comparações internacionais (p. 263-278). Rio de Janeiro : Ed. FGV.

Karasek, R.A. (1979). Job demands, job decision latitude and mental strain : Implications for job redesign. Administrative Science Quarterly, 24, 285-308.

Kergoat, D. (2003). Divisão sexual do trabalho e relações sociais de sexo. In : Marli Emílio, Marilane Teixeira, Miriam Nobre e Tatau Godinho (Orgs.), Trabalho e cidadania ativa para as mulheres : desafios para as Políticas Públicas (pp. 55-63). São Paulo : Coordenadoria Especial da Mulher.

Kergoat, D. (2009). Divisão sexual do trabalho e relações sociais de sexo. In Helena Hirata, Françoise Laborie, Hélène Le Doaré e Danièle Senotier (Orgs.), Dicionário Crítico do Feminismo (pp. 67-75), São Paulo : Editora Unesp.

Lourau, R. (1993). René Lourau na UERJ : Análise Institucional e Práticas de Pesquisa. Rio de Janeiro : UERJ.

Minayo-Gomez, C., \& Lacaz, F.A.C. (2005). Saúde do Trabalhador : novas-velhas questões. Ciência \& Saúde Coletiva, 10, (4), 797-807.

Nowotny, H. (1992). Time and Social Theory - Towards a social theory of time. Time \& Society 1, (3), 421-454.

Oliveira, R.D. (2001). A Reengenharia do Tempo. Rio de Janeiro : Trabalho e Sociedade, 1, (2), 25-29.

Perista, H. (2002). Gênero e trabalho não pago : os tempos das mulheres e os tempos dos homens. Análise Social, 37, (163), 447-474.

Perista, H. (2010). Mulheres, homens e usos do tempo - quinze anos após a Plataforma de Acção de Pequim, onde estamos, em Portugal ? Revista de Estudos Demográficos 47, 47-63.

Perrons, D., Fagan, C., McDowell, L., Ray, K., \& Ward, K. (2005). Work, life and time in the new economy. An introduction. Time \& Society, 14, (1), 51-64. 
Pessanha, J. (2009). A restituição dos resultados de pesquisa : em busca do diálogo entre pesquisadores e trabalhadores de enfermagem. Dissertação de Mestrado, Escola Nacional de Saúde Pública da Fiocruz, Rio de Janeiro, Brasil.

Portela, L. F. (2012). Relações entre o estresse psicossocial no trabalho segundo o modelo demandacontrole e a pressão arterial monitorada : o papel do trabalho doméstico. Tese de doutoramento em Saúde Pública, Escola Nacional de Saúde Pública da Fiocruz, Rio de Janeiro, Brasil.

Portela, L.F., Rotenberg, L., \& Waissmann, W. (2005). Saúde, sono e falta de tempo : relações com o trabalho profissional e doméstico em enfermeiras. Revista de Saúde Pública, 39, (5), 802-808.

Quéinnec, Y. (2007). Horário. Laboreal, 3, (2), 90-91. http://laboreal.up.pt/revista/artigo.php? id=48u56oTV6582234234335473732

Ribeiro-Silva, F. (2006). o dia de quem trabalha à noite: Reflexões sobre o cotidiano de profissionais de enfermagem que trabalham à noite em um hospital público no Rio de Janeiro. Monografia de bacharelado em Psicologia, Universidade do Estado do Rio de Janeiro, Rio de Janeiro, Brasil.

Ribeiro-Silva, F. (2007). A quem pertence o tempo da mulher ? Reflexões sobre o cotidiano de profissionais de enfermagem que trabalham à noite em um hospital público no Rio de Janeiro. In Secretaria Especial de Política para as Mulheres, Ministério da Ciência e Tecnologia, Conselho Nacional de Desenvolvimento Científico e Tecnológico, Ministério da Educação e Fundo de Desenvolvimento das Nações Unidas para a Mulher (Orgs.), 2. Prêmio Igualdade de Gênero (pp. 47-56). Brasília : Presidência da República.

Ribeiro-Silva, F., \& Rotenberg, L. (2008). Tiempo para si y tiempo para otros en mujeres. In $V$ Congreso Internacional Mujer, Trabajo y salud (pp. 176). Zacatecas : Universidad Autónoma de Zacatecas, Universidad Autónoma Metropolitana, Iniciativa Ciudadana y Desarrollo Social, Colegio de Sonora, Centro de Investigación en Alimentación y Desarrollo, Zanzana, Conocimiento y Expresión.

Rotenberg, L., Griep, R.H., Pessanha, J., Gomes, L., Portela, L.F., \& Fonseca, M.J.M. (2010). Housework and recovery from work among nursing teams : a gender view. New Solutions, 20, 497-510.

Rotenberg, L., Portela, L.F., Banks, B., Griep, R.H., Fischer, F.M., \& Landsbergis, P. (2008). A gender approach to work ability and its relationship to professional and domestic work hours among nursing personnel. Applied Ergonomics, 39, 646-652.

Rotenberg, L., Portela, L.F., Marcondes, W.B., \& Moreno, C.R.C. (2001). Sono, cotidiano e vivências de quem troca a noite pelo dia. Cadernos de Saúde Púbica, 17, (3), 639-649.

Schwartz, Y. (2000). A comunidade científica ampliada e o regime de produção de saberes. Trabalho \& Educação, 7, 38-46.

Siegrist, J. (1996). Adverse health effects of high-effort/low-reward conditions. Journal of Occupational and Health Psychology, 1, (1), 27-41.

Silva-Costa, A., Rotenberg, L., Griep, R.H., \& Fischer, F.M. (2011). Relationship between sleeping on the night shift and recovery from work among nursing workers - the influence of domestic work. Journal of Advancec Nursing, 67, (5), 972-981.

Soares, R.E.S. (2005). Tempo, trabalho e modo de vida. Estudo de caso entre profissionais da enfermagem. Dissertação de Mestrado, Departamento de Antropologia da Universidade Federal Fluminense, Niterói, Brasil.

Souza, M.A.S. (2010). As Novas Configurações do Trabalho em Saúde : os indicativos do processo de desregulamentação. Textos \& Contextos, 9, (2), 334 - 344. 
Szalai, A. (1972). The uses of time : Daily Activities of Urban and Suburban Population in Twelve Countries. Paris : Mouton.

Tabboni, S. (2001). The Idea of Social Time in Norbert Elias. Time \& Society, 10, (1), 5-27.

United Nations Development Programme (2002). Implementation of the United Nations Millennium Declaration. Retirado em Janeiro, 9, 2012, de http://www.un.org/millennium/ declaration/ares552e.pdf

Van Veldhoven, M. (2008). Need for recovery after work. An overview of construct, measurement and research. In Jonathan Houdmont e Stavroula Leka (Eds.), Occupational Health Psychology European perspectives on research, education and practice (pp. 1-25). Norttingham : Nottingham University Press.

Verdier, F., Barthe, B., \& Quéinnec ,Y. (2003). Organização do trabalho em turnos : concentrandose na análise ergonômica ao longo das 24 horas. In : Frida Marina Fischer, Claudia Roberta de Castro Moreno e Lúcia Rotenberg (Orgs). 0 trabalho em turnos e noturno na sociedade 24 horas (pp. 137-157). São Paulo : Editora Atheneu.

Zarifian, P. (2002). O tempo do trabalho : o tempo-devir frente ao tempo espacializado. Tempo Social. Revista de Sociologia da USP, 14, (2), 1-18.

\section{RESUMOS}

O artigo aborda os tempos de trabalho profissional e doméstico, com base no pressuposto de que o tempo é a matéria prima através da qual as relações de gênero se expressam nas práticas sociais. A partir da obra de Norbert Elias, busca refletir sobre os tempos de trabalho nas esferas pública e doméstica sob uma perspectiva relacional. As noções de configuração e interdependências são articuladas à proposição de divisão sexual do trabalho (Kergoat, 2009). 0 texto descreve resultados de pesquisas com equipes de enfermagem no Brasil através de técnicas qualitativas e quantitativas. A centralidade do trabalho doméstico permeia a vida das trabalhadoras, demandando a gestão de complexas relações entre as esferas doméstica e profissional, com repercussões à saúde. O texto ressalta a necessidade de instrumentos de investigação sensíveis à divisão sexual do trabalho com vistas a subsidiar discussões sobre políticas sociais voltadas para a reprodução social, como propõem Dedecca, Ribeiro e Ishii (2009) no contexto brasileiro.

El artículo aborda los tiempos de trabajo profesional y las tareas domésticas, a partir del supuesto de que el tiempo es la materia prima a través del cual las relaciones de género se expresan en las prácticas sociales. Desde la obra de Norbert Elias, tiene como objetivo reflexionar sobre el tiempo de trabajo en las esferas pública y doméstica en una perspectiva relacional. Las nociones de configuración y de interdependencias se articulan a la propuesta de la división sexual del trabajo (Kergoat, 2009). El documento describe los resultados de la investigación sobre equipos de enfermería en Brasil a través de técnicas cualitativas y cuantitativas. La centralidad del trabajo doméstico atraviesa la vida de las trabajadoras, exigiendo la gestión de las complejas relaciones entre el ámbito doméstico y profesional, con implicaciones para la salud. El texto pone de relieve la necesidad de instrumentos de investigación sensibles a la división sexual del trabajo con el fin de apoyar los debates sobre las políticas sociales destinadas a la reproducción social, tal como proponen Dedecca, Ribeiro y Ishii (2009) en el contexto brasileño.

Cet article porte sur les temps de travail professionnel et domestique, en partant du principe que le temps est la matière première à travers laquelle les relations de genre s'expriment dans les 
pratiques sociales. À partir de l'œuvre de Norbert Elias, on a voulu envisager le temps de travail dans les sphères publiques et domestiques, en privilégiant une perspective relationnelle. Les notions de configuration et d'interdépendances sont articulées sur celle de la division sexuelle du travail (Kergoat, 2009). Le texte décrit les résultats de recherches menées avec des équipes de soins infirmiers au Brésil, en recourant à des techniques qualitatives et quantitatives. La centralité du travail domestique traverse la vie de ces travailleuses, en exigeant la gestion de relations complexes entre les sphères domestiques et professionnelles, ayant des conséquences pour la santé. L'article souligne la nécessité d'instruments de recherche sensibles à la division sexuelle du travail afin d'enrichir les débats concernant les politiques sociales qui s'inscrivent surtout dans une perspective de reproduction sociale, comme l'ont proposé Dedecca, Ribeiro e Ishii (2009) pour le contexte brésilien.

The article analyzes the time of professional work and housework, with the assumption that time is the raw material through which gender relations are expressed in social practices. From the work of Norbert Elias, the paper aims to reflect on working time in public and domestic spheres in a relational perspective. The notions of configuration and interdependencies are articulated to the proposition of the sexual division of labor (Kergoat, 2009). The paper describes results of research on nursing workers in Brazil through qualitative and quantitative techniques. The centrality of domestic work permeates the lives of workers, demanding the management of complex relationships between the domestic and professional spheres, with implications for health. The text highlights the need for research instruments sensitive to the sexual division of labor in order to support discussions on social policies aimed at social reproduction, as proposed Dedecca, Ribeiro and Ishii (2009) in the Brazilian context.

\section{ÍNDICE}

Mots-clés: rapports de genre, gestion du temps, travail professionnel, travail domestique, santé Keywords: gender relations, time management, professional work, housework, health Palavras-chave: relações de gênero, gestão do tempo, trabalho profissional, trabalho doméstico, saúde

Palabras claves: relaciones de genero, gestión del tiempo, trabajo profesional, trabajo doméstico, salud

\section{AUTOR}

\section{LÚCIA ROTENBERG}

Laboratório de Educação em Ambiente e Saúde, Instituto Oswaldo Cruz, Fiocruz, Rio de Janeiro, Brasil, Av. Brasil 4365, Manguinhos, Pavilhão Lauro Travassos, Rio de Janeiro, RJ, Brasil, 21.045-900

rotenberg@ioc.fiocruz.br 